\title{
Vaginal birth after cesarean section (VBAC) versus emergency repeat cesarean section at teaching hospitals in India: an ICMR task force study
}

\author{
B. S. Dhillon ${ }^{1}$, Nomita Chandhiok ${ }^{1}$, Bharti S. ${ }^{2}$, Bhatia P. $^{3}$, Coyaji K.J. ${ }^{4}$, Das M.C. ${ }^{5}$, Das V. ${ }^{6}$, \\ Davar R.G. ${ }^{7}$, Devambigai S. ${ }^{8}$, Ganguly G. ${ }^{9}$, Ghosh T.K. ${ }^{10}$, Gopalan S. ${ }^{11}$, Habeebulah S. ${ }^{12}$, Idnani \\ R. $^{13}$, Kochar S. ${ }^{14}$, Kodkany B.S. ${ }^{15}$, Madhini V. ${ }^{16}$, Mittal S. ${ }^{17}$, Mukherjee J. ${ }^{18}$, Naphade P.R. ${ }^{19}$, \\ Nevrekar P. ${ }^{20}$, Padmanaban I. ${ }^{21}$, Pagi S.L. ${ }^{22}$, Patnaik S. ${ }^{23}$, Rajarajeswari S. ${ }^{24}$, Salhan S. ${ }^{25}$, Salvi \\ $\mathrm{V}^{26}$, Sanghamitra M. ${ }^{27}$, Sharma S. ${ }^{28}$, Sharma S. ${ }^{29}$, Soni I.J.K. ${ }^{30}$, Sulekha P.B. ${ }^{31}$, Taly A. ${ }^{32}$
}

\begin{abstract}
${ }^{1}$ Division of Reproductive Child Health, Indian Council of Medical Research, New Delhi-110029, India; ${ }^{2}$ I.O.G., Chennai; ${ }^{3}$ Kasturba Hospital, New Delhi; ${ }^{4}$ KEM Hospital, Pune; ${ }^{5}$ Guwahati Medical College, Guwahati; ${ }^{6}$ CSMM University, Lucknow; ${ }^{7}$ Sir J.J. Group of Hospital, Bombay; ${ }^{8}$ Govt. RSRM Hospital, Chennai; ${ }^{9}$ MLN Medical College, Allahabad; ${ }^{10}$ P.G.I.M.E.R. \& SSKM Hospital, Calcutta; ${ }^{11}$ PGIMER, Chandigarh; ${ }^{12}$ JIPMER, Pondicherry; ${ }^{13}$ LLRM Medical College, Meerut; ${ }^{14}$ S.P.Medical College, Bikaner; ${ }^{15} \mathrm{JLN}$ Medical College, Belgaum; ${ }^{16}$ Govt. K.G. Hospital, Chennai; ${ }^{17}$ AIIMS, New Delhi; ${ }^{18}$ R.G. Kar Medical College, Calcutta; ${ }^{19}$ B.J. Medical College, Pune; ${ }^{20}$ Goa Med College, Goa; ${ }^{21}$ Kilpauk Medical College, Chennai; ${ }^{22}$ SSGS Medical College, Baroda; ${ }^{23}$ SCB Medical College, Cuttack; ${ }^{24}$ Madurai Medical College, Madurai; ${ }^{25}$ Safdarjung Hospital, New Delhi; ${ }^{26}$ K.E.M. Hospital, Bombay; ${ }^{27}$ Eden Hospital, Calcutta; ${ }^{28}$ Patna Medical College, Patna; ${ }^{29}$ SMGS Hospital, Jammu; ${ }^{30}$ GSVM Medical College, Kanpur; ${ }^{31}$ SAT Medical College, Thiruvananthapuram; ${ }^{32}$ SMS Medical College, Jaipur
\end{abstract}

Received: 20 June 2014

Accepted: 5 July 2014

\section{*Correspondence:}

Mr. B. S. Dhillon,

E-mail: balwandhillon@gmail.com

(C) 2014 Dhillon BS et al. This is an open-access article distributed under the terms of the Creative Commons Attribution Non-Commercial License, which permits unrestricted non-commercial use, distribution, and reproduction in any medium, provided the original work is properly cited.

\begin{abstract}
Background: Objective of current study was to study the outcome of trial of vaginal birth after Previous Cesarean Section (PCS) and indications for emergency repeat cesarean section at teaching hospitals in India.

Methods: Prospective data was recorded on management practices, associated complications and mortality for a period of 8 months in 2005-2006 at 30 medical colleges/teaching hospitals for delivery.

Results: A total of 155863 deliveries occurred during the study duration, there were $28.1 \%(\mathrm{n}=43824)$ cesarean section and $(10.1 \%)(n=15664)$ were the number of previous cesarean section. In $84 \%(n=13151)$ had repeat cesarean delivery and $2513(16 \%)$ delivered vaginally. A trial of labor was planned in $4035(25.8 \%)$ women. The success rate of VBAC was $62.3 \%$ with 2513 women had successful vaginal delivery and $1522(37.7 \%)$ delivered by emergency repeat cesarean section. Major indication of emergency cesarean section was CPD (52.9\%), foetal distress $(25.8 \%)$, severe PIH/eclampsia (5.0\%), previous 2 CS (0.7\%), APH (1.4\%) and others $(2.7 \%)$. In majority, surgical technique was conventional and in $3.7 \%$ the Misgav-Ladach technique was used. Scar dehiscence and surgical complications were observed in $5.4 \%$ and $4.0 \%$ of cases respectively. Blood transfusion was given in $7.0 \%$ and post-operative complications were seen in 6.8\%. Perinatal and maternal mortality was 18.0/1000 and 257/100000 deliveries respectively.

Conclusions: Safety in childbirth for women with prior cesarean is a major public health concern. Repeat caesarean section and planned vaginal birth after cesarean section are both associated with benefits and harms and correct management represents one of the most significant and challenging issues in obstetric practice.
\end{abstract}

Keywords: Cesarean section, VBAC, Trail of labor, Maternal morbidity 


\section{INTRODUCTION}

For many decades, deliveries by cesarean section were considered as indication for cesarean section in the subsequent pregnancies, reflecting a concern that uterine scar tissue might rupture during labor. ${ }^{1}$ In 1916 Cragin pronounced "once a cesarean, always a cesarean", ${ }^{2}$ was revised in many countries, and a trial of labor in women with history of cesarean section was proposed as an attempt to reduce cesarean section rates. ${ }^{3-6}$ Later because of escalating rates of Cesarean Section (CS), Vaginal Birth After CS (VBAC) has been accepted as a way to reduce the overall cesarean section rates. VBAC is a safe option for many women. ${ }^{7}$ This is true in several countries, where the reproductive pattern is characterized by a pregnancy starting at an early age and high fertility throughout the reproductive years. Therefore after a caesarean section, many women prefer a vaginal birth in order to reduce the consequences and complications of multiple caesarean sections especially for continuing fertility. However, the proportion of women who opt vaginal delivery globally after a prior caesarean delivery has decreased rapidly because of concern about safety. ${ }^{8}$

VBAC offers distinct advantages over repeat caesarean section, since the operative morbidity and mortality are completely eliminated, the hospital stay is much reduced and the expenses involved are much less. The rate of caesarean section needs to be reduced and this can be achieved to a small extent by avoiding a primary caesarean section done without explicit indications and more importantly, by resorting to a trial of vaginal delivery after previous caesarean section, which is safe for the foetus. ${ }^{9}$

The present study was undertaken to ascertain these facts with the hope that more women will be encouraged to avoid an unnecessary repeat cesarean section by opting for vaginal delivery.

\section{METHODS}

The Indian Council of Medical Research (ICMR) has a network of Human Reproduction Research Centre (HRRC) located in the department of obstetrics and gynecology of 30 medical colleges/teaching hospitals in various parts of the country. Prospective data was recorded through proforma on management practices, associated complications and mortality for a period of 8 months in 2005-2006 on 15664 consecutive cases of previous cesarean section reporting at 30 medical colleges/teaching hospitals for delivery. Information on the patient's characteristics including age, parity, booked, non-booked status, past obstetric medical and surgical history, history of present pregnancy and complication was collected. The mode of delivery was recorded as Elective Repeat Cesarean Section (ERCS) or Emergency Repeat Cesarean Section (EmRCS).
In case of vaginal delivery it was recorded whether it was spontaneous vaginal delivery, forceps or ventouse. Maternal complications developed during or after the labor was noted for example, scar tenderness, scar dehiscence etc. The women were followed up from admission to discharge from the hospital.

\section{Statistical analysis}

Statistical analysis was performed using SPSS 15.0 for windows and various descriptive statistics were used to calculate frequencies, percentages, means and standard deviation. The association of various maternal characteristics with VBAC was assessed by using Chisquare test. Yates correction for continuity was carried out in 2 by 2 tables.

\section{RESULTS}

A total of 155863 deliveries took place in the study duration, out of which 43824 (28.1\%) were the number of cesarean section and $15664(10.1 \%)$ were the number of previous cesarean section (Table 1). An overall increase of approximately $2.7 \%$ in cesarean section rates was observed during a period of 7 years ago in the same set of hospitals, from $25.4 \%$ in $1998-99^{10}$ to $28.1 \%$ in $2005-06$. The average age of the women delivering by cesarean was $26.1 \pm 3.9$ years. Majority of women $(89.5 \%)$ were $2^{\text {nd }}$ and $3^{\text {rd }}$ gravida and $74.5 \%$ of the women were parity two. $42.1 \%$ of the women who came for delivery in the hospital were from rural areas and $88.8 \%$ of these women were booked cases and among these $73.2 \%$ were booked at HRRC.

Of 15664 women with history of cesarean, 2513 (16\%) women delivered vaginally and $13151(84 \%)$ underwent repeat cesarean section. Out of the 4035 women who were allowed a trial of labor, $2513(62.3 \%)$ delivered vaginally and $1522(37.7 \%)$ delivered by emergency repeat cesarean section mainly done for abnormal presentations, placenta praevia, and severe intrauterine growth retardation. Thus the success rate of VBAC was $62.3 \%$.

Of those 784 women whose primary cesarean section was done for CPD, $61.0 \%$ delivered vaginally, whereas $61.4 \%$ and $66.1 \%$ of women who underwent primary cesarean section for foetal distress and malpresentation delivered vaginally. (Table $3 \mathrm{P}=0.54 \& \mathrm{P}=0.02$ respectively).

Among vaginal delivery 587 (23.4\%) had spontaneous delivery, $1615(64.3 \%)$ with episiotomy, $256(10.2 \%)$ with forceps and $55(2.2 \%)$ with ventouse. Indications for emergency cesarean section have been analyzed in several broad categories namely: CPD (52.9\%), foetal distress (25.8\%), severe PIH/eclampsia (5.0\%), malpresentation $(1.9 \%)$, failed induction $(6.2 \%)$, others $(2.7 \%)$ (Table 4). The majority of the women had cesarean section for more than one indication was the main indication for emergency cesarean section. 
There was no difference in the successful VBAC across age groups. There was a significant association between birth weight and successful VBAC. With low birth weight (birth weight less than $2500 \mathrm{~g}$ ), VBAC was $73.0 \%$. It was $58.6 \%$ for birth weight in the range 2500 to $4000 \mathrm{~g}$. Those with more than $4 \mathrm{~kg}$, VBAC was $44.4 \%$ (P value $=0.00)$. This confirms that increasing birth weight is associated with more cesarean section. In those with 37 or more weeks of gestation, VBAC was $60.5 \%$ and in less than 37 weeks VBAC was $67.5 \%$ (P value $=0.039)$ which shows that there is relationship between gestational age and VBAC. With completed 40 weeks and above VBAC rate was $56.4 \%$. It is known that there is a slight increase in failure of VBAC in those after 40 weeks. ${ }^{11}$
$83.2 \%$ of the women with previous caesarean section, who also had a prior vaginal delivery, delivered vaginally, as compared to $60.3 \%$ of the women who did not undergo prior vaginal delivery $(\mathrm{P}$ value $=0.000)$. This difference was statistically significant (Table 2).

Out of the 3452 women who were in spontaneous labor, $63.7 \%$ delivered vaginally, whereas out of the 368 who were induced with oxytocin, $54.6 \%$ delivered vaginally ( $\mathrm{P}$ value $=0.0007)$. This is statistically significant difference. Induction of labor with prostaglandins was attempted in 215 patients $(5.3 \%)$ and 113 cases delivered by successful VBAC $(52.6 \%)$.

Table 1: Rate (\%) of cesarean sections \& previous cesarean section and current study samples in 30 teaching hospital/medical colleges.

\begin{tabular}{|c|c|c|c|c|c|c|}
\hline \multirow[t]{2}{*}{ HRRC } & \multirow{2}{*}{$\begin{array}{l}\text { No. of } \\
\text { deliveries } \\
\text { n }\end{array}$} & \multicolumn{2}{|c|}{$\begin{array}{l}\text { No. of caesarean } \\
\text { section }\end{array}$} & \multicolumn{2}{|c|}{$\begin{array}{l}\text { No. of previous } \\
\text { caesarean section }\end{array}$} & \multirow{2}{*}{$\begin{array}{l}\text { Trial of } \\
\text { labour } \\
\text { n }\end{array}$} \\
\hline & & $\mathbf{n}$ & $\%$ & $\mathbf{n}$ & $\%$ & \\
\hline Medical College, Jammu & 9781 & 2690 & 27.5 & 712 & 7.3 & 489 \\
\hline PGIMER, Chandigarh & 2711 & 780 & 28.8 & 367 & 13.5 & 158 \\
\hline K.H., New Delhi & 7879 & 1131 & 14.4 & 374 & 4.7 & 72 \\
\hline S.J.H., New Delhi & 14121 & 2252 & 15.9 & 684 & 4.8 & 387 \\
\hline A.I.I.M.S., New Delhi & 1511 & 465 & 30.8 & 245 & 16.2 & 153 \\
\hline S.P. Medical College, Bikaner & 4291 & 862 & 20.1 & 256 & 6.0 & 35 \\
\hline K.G. Medical College, Lucknow & 2222 & 983 & 44.2 & 292 & 13.1 & 68 \\
\hline M.L.N. Medical College, Allahabad & 383 & 225 & 58.7 & 85 & 22.2 & 20 \\
\hline G.S.V.M. Medical College, Kanpur & 667 & 277 & 41.5 & 95 & 14.2 & 22 \\
\hline L.L.R. Medical College, Meerut & 1400 & 162 & 11.6 & 41 & 2.9 & 14 \\
\hline S.M.S. Medical College, Jaipur & 7924 & 2300 & 29.0 & 525 & 6.6 & 286 \\
\hline I.O.G., Chennai & 11835 & 5093 & 43.0 & 2007 & 17.0 & 248 \\
\hline Kilpauk Medical College, Chennai & 5313 & 1793 & 33.7 & 729 & 13.7 & 164 \\
\hline K.G.H. Chennai & 7415 & 2774 & 37.4 & 1229 & 16.6 & 33 \\
\hline Madurai Medical College, Madurai & 8442 & 1372 & 16.3 & 1115 & 13.2 & 84 \\
\hline S.A.T. Medical College, Thiruvanantpuram & 10651 & 3133 & 29.4 & 1404 & 13.2 & 357 \\
\hline R.S.R.M., Chennai & 8602 & 2501 & 29.1 & 1101 & 12.8 & 155 \\
\hline J.L.N. Medical College, Belgaum & 2830 & 663 & 23.4 & 297 & 10.5 & 152 \\
\hline Patna Medical College, Patna & 3478 & 1000 & 28.8 & 317 & 9.1 & 1 \\
\hline R.G.Kar, Kolkatta & 8932 & 2705 & 30.3 & 921 & 10.3 & 109 \\
\hline Eden Hospital, Kolkatta & 5510 & 2404 & 43.6 & 441 & 8.0 & 32 \\
\hline Medical College, Guwahati & 5371 & 2155 & 40.1 & 344 & 6.4 & 94 \\
\hline S.C.B.Medical College, Cuttack & 4349 & 1621 & 37.3 & 304 & 7.0 & 86 \\
\hline S.S.K.M. Hospital, Kolkatta & 1003 & 558 & 55.6 & 110 & 11.0 & 5 \\
\hline S.S.G.S. Medical College, Baroda & 2803 & 480 & 17.1 & 336 & 12.0 & 197 \\
\hline K.E.M. Hospital, Mumbai & 5373 & 1139 & 21.2 & 512 & 9.5 & 281 \\
\hline K.E.M .Hospital, Pune & 978 & 403 & 41.2 & 169 & 17.3 & 13 \\
\hline J.J. Hospital, Mumbai & 1483 & 307 & 20.7 & 88 & 5.9 & 46 \\
\hline B.J. Medical College, Pune & 5116 & 747 & 14.6 & 320 & 6.3 & 165 \\
\hline Goa Medical College, Goa & 3489 & 849 & 24.3 & 341 & 9.8 & 109 \\
\hline Total & 155863 & 43824 & 28.1 & 15664 & 10.1 & 4035 \\
\hline
\end{tabular}


Blood loss was more than $1000 \mathrm{ml}$ in $8.0 \%$ of TOL where as in VBAC it was only $(0.3 \%)$ as compared to EmRCS $20.6 \%$ ( $P=0.000$ highly significant). Blood transfusion rates was $3.7 \%$ and it was $1.8 \%$ in VBAC versus $20.6 \%$ in EmRCS $(\mathrm{P}=0.000$ highly significant). Of those 12 women only 2 cases of uterine rupture was reported in VBAC $(\mathrm{P}=0003)$. Dehiscence of scar in VBAC was 6 $(6.8 \%)$ as compared to $82(93.2 \%)$ in EmRCS $(\mathrm{P}=$ $0.000)$.

Table 2: Vaginal birth among women on trial of labour and other maternal characteristics.

\begin{tabular}{|c|c|c|c|c|c|c|c|}
\hline \multirow[t]{2}{*}{ Characteristics } & \multicolumn{2}{|c|}{ Vaginal birth } & \multirow[t]{2}{*}{$\begin{array}{l}\text { Emergency } \\
\text { caesarean }\end{array}$} & \multirow[t]{2}{*}{ Total } & \multirow[t]{2}{*}{$x^{2}$} & \multirow[t]{2}{*}{ d.f. } & \multirow[t]{2}{*}{ P value } \\
\hline & $\mathbf{n}$ & $\%$ & & & & & \\
\hline \multicolumn{8}{|c|}{ Maternal age at birth in years } \\
\hline$<20$ & 22 & 64.7 & 12 & 34 & \multirow{5}{*}{0.35} & \multirow{5}{*}{4} & \multirow{5}{*}{0.98} \\
\hline $21-24$ & 923 & 62.0 & 565 & 1488 & & & \\
\hline $25-29$ & 1098 & 62.2 & 667 & 1765 & & & \\
\hline $30-34$ & 382 & 63.1 & 223 & 605 & & & \\
\hline$\geq 35$ & 88 & 61.5 & 55 & 143 & & & \\
\hline \multicolumn{8}{|l|}{ Parity } \\
\hline 1 & 1601 & 55.8 & 1267 & 2868 & \multirow{2}{*}{175.9} & \multirow{2}{*}{1} & \multirow{2}{*}{0.000} \\
\hline$>1$ & 912 & 78.1 & 255 & 1167 & & & \\
\hline \multicolumn{8}{|l|}{ Birth weight } \\
\hline Low (<2.5 Kg.) & 721 & 73.0 & 266 & 987 & \multirow{4}{*}{67.9} & \multirow{4}{*}{2} & \multirow{4}{*}{0.000} \\
\hline Normal (2.5-4.0) & 1756 & 58.6 & 1239 & 2995 & & & \\
\hline Overweight (>4.0) & 8 & 44.4 & 10 & 18 & & & \\
\hline Not recorded & 28 & - & 7 & 35 & & & \\
\hline \multicolumn{8}{|c|}{ Birth interval in months } \\
\hline$\leq 12$ & 109 & 62.6 & 65 & 174 & \multirow{5}{*}{8.4} & \multirow{5}{*}{3} & \multirow{5}{*}{0.039} \\
\hline $13-24$ & 858 & 63.1 & 501 & 1359 & & & \\
\hline $25-36$ & 773 & 63.5 & 444 & 1217 & & & \\
\hline$\geq 37$ & 641 & 58.3 & 459 & 1100 & & & \\
\hline Not recorded & 44 & - & 24 & 68 & & & \\
\hline \multicolumn{8}{|l|}{ Gestational age } \\
\hline$<37$ weeks & 521 & 67.5 & 251 & 772 & \multirow{3}{*}{12.75} & \multirow{3}{*}{1} & \multirow{3}{*}{0.0003} \\
\hline$\geq 37$ weeks & 1904 & 60.5 & 1242 & 3146 & & & \\
\hline Not recorded & 88 & - & 29 & 117 & & & \\
\hline \multicolumn{8}{|c|}{ Mode of delivery in last viable delivery } \\
\hline Vaginal birth & 307 & 83.2 & 62 & 369 & \multirow{2}{*}{75.63} & \multirow{2}{*}{1} & 0000 \\
\hline Caesarean & 2206 & 60.2 & 1460 & 3666 & & & 0.000 \\
\hline Total & 2513 & 62.3 & 1522 & 4035 & & & \\
\hline
\end{tabular}

Table 3: Indications for primary caesarean section and outcome of trial of labour.

\begin{tabular}{|c|c|c|c|c|c|c|}
\hline \multirow{2}{*}{$\begin{array}{l}\text { Indication for primary } \\
\text { caesarean section } \\
\text { (multiple response) }\end{array}$} & \multicolumn{2}{|c|}{$\begin{array}{l}\text { VBAC } \\
(n=2513)\end{array}$} & \multicolumn{2}{|c|}{$\begin{array}{l}\text { Emergency } \\
\text { caesarean } \\
(n=1522)\end{array}$} & \multirow[t]{2}{*}{ Total } & \multirow[t]{2}{*}{$\begin{array}{l}P \\
\text { value }\end{array}$} \\
\hline & $\mathbf{n}$ & $\%$ & $\mathbf{n}$ & $\%$ & & \\
\hline Failed induction & 105 & 34.5 & 199 & 65.5 & 304 & 0.00 \\
\hline CPD & 478 & 61.0 & 306 & 39.0 & 784 & 0.40 \\
\hline $\mathrm{APH}$ & 96 & 73.3 & 35 & 26.7 & 131 & 0.008 \\
\hline Foetal distress & 774 & 61.4 & 487 & 38.6 & 1261 & 0.54 \\
\hline Malpresentation & 449 & 66.1 & 230 & 33.9 & 679 & 0.023 \\
\hline Previous CS & 27 & 77.1 & 8 & 22.9 & 35 & 0.08 \\
\hline Severe PIH/eclampsia & 158 & 51.6 & 148 & 48.4 & 306 & 0.000 \\
\hline Others & 75 & 59.1 & 52 & 40.9 & 127 & 0.446 \\
\hline
\end{tabular}


Post-operative complication was $2.8 \%$ cases in TOL where as in VBAC $(0.4 \%)$ as compared to $6.8 \%$ in emergency cesarean section $(\mathrm{P}=0.000$ highly significant). Maternal death was reported in 6 cases of VBAC as compared to 4 cases in emergency cesarean cases $(P=0.85)$ which was not statistically significant.

The average duration of hospital stay for VBAC was 4.5 \pm 3.9 days as compared to emergency cesarean section $10.6 \pm 5.0$.

This shows that women who had a successful VBAC had a significantly lesser duration of hospital stay as compared to those had a cesarean section $(\mathrm{P}=0.000$ highly significant).

Table 4: Indications for emergency repeat caesarean section.

\begin{tabular}{|lll|}
\hline $\begin{array}{l}\text { Indication for current } \\
\text { caesarean section } \\
\text { (multiple response) }\end{array}$ & $\begin{array}{l}\text { Caesarean section } \\
\text { (n=1522) }\end{array}$ \\
\hline Failed induction & 94 & \% \\
\hline CPD & 805 & 52.9 \\
\hline APH & 22 & 1.4 \\
\hline Foetal distress & 392 & 25.8 \\
\hline Malpresentation & 29 & 1.9 \\
\hline Previous 2 CS & 10 & 0.7 \\
\hline Severe PIH/eclampsia & 76 & 5.0 \\
\hline Others & 41 & 2.7 \\
\hline
\end{tabular}

\section{DISCUSSION}

There has been a steady rise in cases with previous cesarean section over the past few decades. However, the rate of caesarean section is rising in many countries over the past 10 years. Miller et al. reported a post caesarean pregnancy rate of $8.1 \%$ in 1983 and $14.1 \%$ in $1992 .{ }^{2}$ Bhat BPR et al. reported post caesarean pregnancy rate of $8.7 \% .^{12}$ Our study showed a post caesarean pregnancy rate of $10.1 \%$. Published literature shows that there has been $60 \%$ to $80 \%$ success in attempts at VBAC. Dhall et.al. ${ }^{13}$ has reported that around $76 \%$ of women with PCS undergoing trial of labor have vaginal delivery. Singh et.al. ${ }^{14}$ report $65 \%$ VBAC. We had a $62.3 \%$ success in those who had trial of labour. McMohan et al. ${ }^{15}$ have reported vaginal delivery in $66 \%$ of those with dystocia, $84 \%$ of those with malpresentation and $75 \%$ of those with fetal distress as indication of PCS. Our respective figures are $68 \%, 38 \%$ and $77 \%$. Aisien et al. reported a $48.1 \%$ incidence of vaginal delivery in previous caesarean section $\operatorname{cases}^{16}$, whereas Chhabra et.al reported an incidence of $32.4 \% .^{17}$ Our study reported a $16 \%$ incidence of vaginal delivery in previous caesarean section.

Many factors have been put forward in international journals for the upward trend of caesarean section, like reduced parity, older primipara, use of electronic foetal monitoring, delivery of breech by cesarean section, less use of forceps, fear of litigation and high socio-economic status. ${ }^{18}$ The recommendation for optimal caesarean section rate of $10-15 \%$ was made by WHO in $1985 .{ }^{19}$ Even though the successful VBAC is considered safer than routine repeat caesarean section, the enthusiasm for VBAC is found to be decreasing now due to several reasons. Many women demand for repeat elective caesarean section in order to avoid a painful natural birth. This is mainly due to inadequate patient information. Caesarean operation is now considered to be a safe surgery due to safe anesthesia, better surgical technique, and antibiotic and thrombo prophylaxis. Therefore, many doctors also prefer to do caesarean section in order to avoid litigation. A number of factors are associated with successful vaginal birth after previous caesarean section. Previous vaginal birth was the single best predictor for successful VBAC. ${ }^{20}$ Success of VBAC is less if the prior indication was non-progression of labour and cephalopelvic disproportion. ${ }^{21}$ Literature search showed that maternal age of more than 30 years, male fetus, no prior vaginal delivery, prostaglandin induction, excessive weight gain during pregnancy and maternal body mass index of more than 30 are associated with poor VBAC success rate. ${ }^{22}$

There is a significant reduction in trial of scar globally due to concerns of safety especially attributed to uterine rupture. ${ }^{8}$ Patients should be counseled that uterine rupture can occur before labor starts and planning a repeat section is no guarantee of safety. The decline in VBAC is seen in many countries may be due to a reduction in trial of labor attempts and not due to a change in success rate. Maternal satisfaction is more after vaginal delivery. ${ }^{23}$

The average length of stay was 4.5 days in the patients who delivered vaginally as compared to 10.6 days in those who had emergency caesarean section. This was comparable with other studies.

\section{CONCLUSION}

Safety in childbirth for women with prior cesarean is a major public health concern. Repeat caesarean section and planned vaginal birth after caesarean section are both associated with benefits and harms and correct management represents one of the most significant and challenging issues in obstetric practice.

Funding: The study was funded by Indian council of medical research

Conflict of interest: None declared

Ethical approval: The study was approved by the institutional ethics committee

\section{REFERENCES}

1. Van Bogaert LJ. Mode of delivery after one cesarean section. Int J Gynecol Obstet. 2004;87:9-13. 
2. Craigin EB. Conservatism in obstetrics. N Y Med J. 1916;104:1-3.

3. Miller AD, Diaz FG, Paul RH. Vaginal birth after caesarean: a 10 year experience. Obstet Gynecol. 1994;84:255-8.

4. Rosen MG, Dickinson JC, Westhoff CL. Vaginal birth after cesarean: a meta-analysis of morbidity and mortality. Obstet Gynecol. 1991;77:465-70.

5. Rageth JC, Juzi C, Grossenbacher H. Delivery after previous cesarean: a risk evaluation. Swiss Working Group of Obstetric and Gynecologic Institutions. Obstet Gynecol. 1999;93:332-7.

6. Mozurkewich EL, Hutton EK. Elective repeat cesarean delivery versus trial of labor: a metaanalysis of the literature from 1989 to 1999. Am J Obstet Gynecol. 2000;183:1187-97.

7. Editorial. Vaginal delivery after caesarean section. Br Med J. 2004;329:359-60.

8. Landon MB, Hauth JC, Leveno KJ, Catherine et al. Maternal and perinatal outcomes associated with a trial of labor after prior caesarean delivery. $\mathrm{N}$ Engl $\mathrm{J}$ Med. 2004;351:2581-9.

9. Vardhan S, Behera RC, Sandhu GS, Singh A, Bandhu HC. Vaginal birth after caesarean delivery. J Obstet Gynecol India. 2006;56(4):320-3.

10. Kambo I, Bedi N, Dhillon BS, Saxena NC. A critical appraisal of cesarean section rates at teaching hospitals in India. Int $\mathbf{J}$ Gynecol Obstet. 2002;79:151-8.

11. Coassolo KM, Stamilio DM, Pare E, Peipert JF. Safety and efficacy of VBAC at or beyond 40 weeks gestation. Obstet Gynecol. 2005;106:700-6.

12. Bhat BPR, Savant R, Kamath A. Outcome of a post caesarean pregnancy in a tertiary center of a developing country. J Clin Diag Res. 2010:4(1):2005-9.

13. Dhall K, Mittal SC, Grover V et al. Childbirth following primarycesarean section-evaluation of a scoring system. Int J Gynecol Obstet. 1987;25:199201.
14. Singh T, Clark SC, Toffel S. Changes in cesarean delivery in the United States, 1988 and 1993. Birth 1995;22:63-7.

15. Mc Mohan MJ, Luther ER, Bowes WA et al. Comparison of a trial of labor with an elective second cesarean section. $\mathrm{N}$ Engl J Med. 1996;335:689-95.

16. Aisien AO, Oronsaye AU. Vaginal birth after one previous caesarean section in a tertiary institute in Nigeria. J Obstet Gynecol. 2004;24(8):886-90.

17. Chhabra S, Arora G. Delivery in women with one previous caesarean section. J Obstet Gynecol India. 2006;56(4):304-7.

18. Goldman G, Pineault R, Potvin L, Blais R, BIlodeau $H$. Factors influencing the practice of vaginal birth after caesarean section. Am J Public Health. 1993;8:1104-8.

19. World Health Organization. Appropriate technology for birth. Lancet. $1985 \mathrm{Aug}$;2(8452):436-7.

20. Ghaffari A, Ahmed BB. Safety of vaginal birth after cesarean delivery. Int $\mathbf{J}$ Gynecol Obstet. 2006;92(1):38-42.

21. Peaceman A, Gersnoviez R, Landon M et al. The MFMU cesarean registry: impact of fetal size on trial of labor success for patients with previous cesarean for dystocia. Am J Obstet Gynecol. 2005;195(4):1127-31.

22. G. Puliyath. Vaginal birth after caesarean section (VBAC): a descriptive study from Middle East. Intern J Gynecol Obstet. 2010;12(2):20.

23. Dunn C, O'Herlihy. Comparison of maternal satisfaction following vaginal delivery after caesarean section and caesarean section after previous vaginal delivery. Eur J Obstet Gynecol Reprod Biol. 2005;121(1):56-60.

DOI: $10.5455 / 2320-1770$. ijrcog20140933

Cite this article as: Dhillon BS, Chandhiok N, Bharti S, Bhatia P, Coyaji KJ, Das MC, et al. Vaginal birth after cesarean section (VBAC) versus emergency repeat cesarean section at teaching hospitals in India: an ICMR task force study. Int J Reprod Contracept Obstet Gynecol 2014;3:592-7. 